\section{GESTÃO DO PROGESSO DE PROJETO ATRAVÉS DO BIM}

Modalidade: Experiência de ensino-aprendizagem BIM realizadas

\section{REALIZACẼO DO WORKSHOP}

\section{A turma foi dividida em grupos. Cada} componente do grupo assumiu uma das seguintes funções: [1] responsável pela coordenação do projeto [2] responsável pela compatibilização [3] responsável pelo lançamento estrutural; [4] responsável pelo desenvolvimento do projeto das instalações hidráulicas (água fria e quente); e [5] responsável pelo desenvolvimento do projeto das instalações de esgoto sanitário e águas pluviais.

Gráfico 1: Pontos positivos da experiência

\section{COMPREENSÃO SOBRE IFC \\ COMPREENSÃO SOBRE USOS BIM \\ PRÁTICA DE PROJETO COLABORATIVO}

COMPREENSÃO SOBRE COORDENAÇÃO E COMPATIBILIZAÇÃO

TRANSFERÊNCIA DO APRENDIZADO PARA A PRÁTCA PROFISSIONAL

APRENDIZADO DE NOVAS FERRAMENTAS

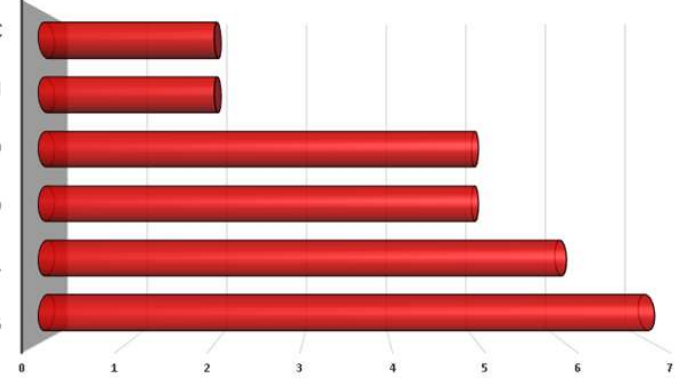

Figura 1, 2, 3: Alguns resultados do trabalho realizado pelos discentes que participaram do workshop

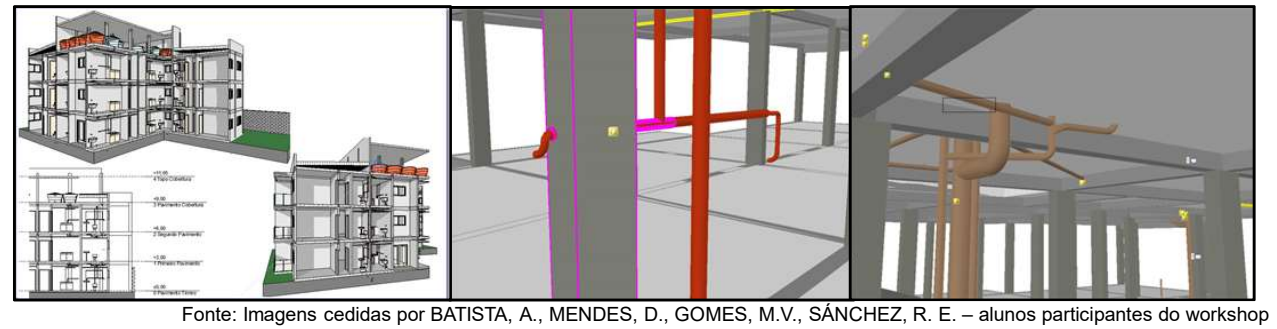

Os alunos consideraram a experiência positiva, embora parte acredite que 0 tempo foi curto. $O$ fato da atividade partir de uma solução arquitetônica prédefinida foi considerado adequado, uma vez que o foco da experiência foi 0 gerenciamento e a coordenação de projetos. A quase totalidade dos alunos informou que a experiência permitiu identificar as questões de gestão e coordenação de projetos.
Ao final da atividade, os grupos apresentaram os documentos evidenciando o desenvolvimento do projeto compatibilizado, e também 0 relatório com as atas das reuniões, atualização do cronograma e relato dos problemas de gestão do processo de projeto encontrados indicando pendências.

Para identificar os pontos fortes e fracos da experiência, um questionário foi enviado aos alunos que expressaram sua opinião sobre a atividade. aspectos positivos identificados pelos discentes, com destaque para o aprendizado de novas ferramentas. $\mathrm{E}$ entre as dificuldades, a falta de interoperabilidade entre as versões de algumas ferramentas - problema que foi resolvido através do IFC. A partir dos resultados obtidos com essa experiência, pretende-se a criação de disciplina a ser oferecida em caráter

\section{LIÇÕES APRENDIDAS}

Mônica S Salgado

Aline C. Marques

Cristiane L. Canuto

Eduardo R. dos Santos

1- PROARQ FAU UFRJ, monicassalgado@fau.ufrj.br 2- PROARQ FAU UFRJ, alinecalazans@fau.ufrj.br 3- PROARQ FAU UFRJ, cristiane.canuto@fau.ufrj.br 4 - PROARQ FAU UFRJ eduardo.ribeiro@fau.ufrj.br

\section{INTRODUÇÃO}

A presente atividade teve por objetivo a realização de uma experiência de projeto colaborativo, usando as ferramentas que operam na Plataforma BIM. O objetivo foi o aprofundamento no uso das ferramentas na coordenação e compatibilização de projetos. O workshop foi realizado em 20 horas ( 10 dias). Participaram alunos inscritos na disciplina "Gestão do Processo de Projeto", que declararam conhecimento no uso das ferramentas BIM. Os grupos exploraram as possibilidades oferecidas no desenvolvimento do projeto das disciplinas complementares; na compatibilização; na colaboração no desenvolvimento de projetos; e na coordenação e gestão do processo de projeto.

\section{AGRADECIMENTOS} optativo aos alunos da FAU UFRJ.
$O$ presente trabalho foi realizado com apoio da Coordenação de Aperfeiçoamento de Pessoal de Nível Superior - Brasil (CAPES) - Código de Financiamento 001. Os autores também agradecem ao $\mathrm{CNPq}$. 